\title{
Comparison of nucleolar organiser regions and DNA flow cytometry in the evaluation of pleural effusion
}

\author{
Ming-Shyan Huang, Mee-Sun Tsai, Jhi-Jhu Hwang, Tung-Heng Wang
}

\begin{abstract}
Background - In conventional cytological diagnosis of pleural effusions the assessment of morphological features plays an important part. However, false negative and false positive results may occur. In this study conventional cytology was compared with flow cytometric DNA analysis and the argyrophil staining technique for nucleolar organiser regions (AgNOR) to characterise benign and malignant effusions.

Methods - Pleural effusions from 71 patients (38 with benign lung disease, 33 with proven adenocarcinoma of lung) were studied by conventional cytology, flow cytometric DNA analysis, and the AgNOR technique. Tumour cell ploidy was determined by flow cytometry. In an attempt to detect the cell proliferative state, flow cytometric $S$ phase fraction and the AgNOR technique were used. The correlations among conventional cytology, flow cytometric DNA ploidy, $S$ phase fraction analysis, and nucleolar organiser regions were investigated.
\end{abstract}

Results - All the 38 benign pleural effusions were diploid. There were $17(52 \%)$ aneuploid and $16(48 \%)$ diploid malignant pleural effusions. Based on these results this type of DNA analysis had a sensitivity of $52 \%$ and a specificity of $100 \%$. The mean (SD) numbers of flow cytometric $S$ phase fractions of benign and malignant cases were $5.32(1.67) \%$ and $12.45(3.93) \%$ respectively. The mean numbers of $S$ phase fractions of diploid malignant cases were higher than diploid benign cases. In each case the number of AgNORs was counted in 100 cells. The mean number of $\mathrm{AgNOR}$ dots per nucleus was $12.57(3.64)$ for malignant pleural effusion cells and $3.96(1 \cdot 39)$ for benign pleural effusion cells. The mean number of AgNOR dots was 14.45 (3.36) for aneuploid malignant pleural effusion cells and $10.57(2 \cdot 82)$ for diploid malignant pleural effusion cells. The AgNOR numbers were higher in diploid malignant cells than in diploid benign cells. There was a significant correlation between the $S$ phase fraction determined by.flow cytometry and the mean number of AgNORs per nucleus in malignant cases.

Conclusions-Both flow cytometry and the AgNOR methods provide comparable measurements in the diagnosis of pleural effusion. The study also indicates that the
AgNOR method, which is rapid and easy to perform, may be a useful adjunct to flow cytometry, $S$ phase fraction analysis and conventional cytology in the routine diagnosis of malignant pleural effusion.

(Thorax 1994;49:1152-1156)

The diagnosis of a pleural effusion is often difficult. In making a cytological diagnosis, the assessment of morphological features plays a very important part. However, false negative and false positive results can occur due to scarcity of recognisable malignant cells and abnormalities of mesothelial cells and macrophages in the sediment. ${ }^{1}$ For these reasons various diagnostic methods have been used to identify tumour cells.

Several experimental techniques have been used to improve the diagnosis of effusions such as transmission and scanning electromicroscopy, ${ }^{2}$ cytochemistry, ${ }^{3}$ and cytogenetics. ${ }^{4}$ Chromosomal abnormalities strongly suggest that a problem exists ${ }^{5-7}$ and, because these abnormalities may be expressed as an abnormal DNA content, measuring DNA for diagnostic purposes has been repeatedly attempted by flow cytometry. ${ }^{8-10}$ DNA analysis using automated flow cytometry is rapid and permits evaluation of a large number of cells from an effusion.

Nucleolar organiser regions (NOR) are loops of DNA in the nucleus which code for ribosomal RNA and are thus significant in the synthesis of protein. ${ }^{11}$ These regions are associated with acidic non-histone proteins that can be visualised by argyrophilic staining (AgNOR). ${ }^{12}$ The use of the AgNOR technique in histopathology ${ }^{13-17}$ in numerous neoplastic tissues has shown that the distribution pattern of AgNORs is helpful in the diagnosis of malignancy.

In this study the pleural effusions were analysed by conventional cytology, DNA flow cytometry, and the AgNOR technique and the results were compared.

\section{Methods}

Pleural effusion samples from 71 patients admitted to the Department of Internal Medicine of Kaohsiung Medical College Hospital were analysed by conventional cytology, flow cytometry DNA analysis, and the AgNOR technique. In all patients the diagnosis was confirmed either by histology or clinical data. 


\section{CONVENTIONAL CYTOLOGY}

Fluids were centrifuged at $600 \mathrm{~g}$ for 10 minutes. The supernatant was discarded and a drop of the sediment was placed on a clear glass slide. Smears were made and fixed in $95 \%$ ethanol for 30 minutes. The Papanicolaou stain was used, and the smears were screened and evaluated routinely as either negative for malignant cells, insufficient for diagnosis, suspicious, or positive for malignant cells. The "positive" cytology result was designated when the cytological examination revealed a suspicious or positive result.

\section{FLOW CYTOMETRY}

Specimens were prepared for flow cytometric studies by the technique of Schneller et $a l^{18}$ Briefly, specimens of fresh pleural fluid were centrifuged at $600 \mathrm{~g}$ for 10 minutes. After centrifugation the supernatant was decanted and cell pellets were resuspended in $10 \mathrm{ml}$ of cold citrate buffer. The suspension was then incubated at room temperature for 20 minutes, with periodic agitation every five minutes. The material was subsequently washed two or three times in cold citrate buffer. Each wash was centrifuged until a clear supernatant was obtained. Cells were filtered through a $30 \mu \mathrm{m}$ pore nylon mesh filter and centrifuged at $200 \mathrm{~g}$ at $4^{\circ} \mathrm{C}$ for 15 minutes to pellet the nuclei. The nuclear pellet was resuspended in cold citrate buffer and a $0.5 \mathrm{ml}$ aliquot containing $5 \times 10^{5}$ cells was resuspended in $1.7 \mathrm{ml}$ of $0.1 \%$ sodium citrate containing $0.05 \mathrm{mg} / \mathrm{ml}$ propidium iodide (Sigma, St. Louis, Missouri, USA). The suspensions were allowed to equilibrate with propidium iodide at $4^{\circ} \mathrm{C}$ for 30 minutes in the dark. The specimens were analysed on a Becton Dickinson FASCan (San Jose, California, USA) equipped with a $15 \mathrm{~mW}, 488 \mathrm{~nm}$ argon ion laser. At least 10000 cells were measured with the use of Consort 30 software (Becton Dickinson) for data acquisition and the DNA cell cycles analysis software for DNA ploidy and $S$ phase fraction analysis. Normal human lymphocytes served as a normal DNA (diploid) content control. The flow cytometry results were categorised as either normal (diploid) or abnormal (aneuploid). ${ }^{18}$ Aneuploidy was defined in this study as having one or more distinct separate peaks compared with the $G_{0} / G_{1}$ and $G_{2} M$ peaks of the diploid cell population. The DNA index was obtained from the ratio of channel numbers of the abnormal peak to the modal channel numbers of the diploid peak. The coefficient of variation of $G_{0} / G_{1}$ cells of both normal and abnormal populations ranged from $1 \cdot 1 \%$ to $7 \cdot 6 \%$ with a mean of $3 \cdot 8 \%$. DNA histograms with a coefficient of variation of more than $9 \%$ were excluded from this study. The "positive" flow cytometry result was designated when aneuploidy was detected.

\section{AgNOR TECHNIQUE}

Fresh fluid was received by the laboratory and each sample was centrifuged at $600 \mathrm{~g}$ for 10 minutes. The sediment was placed on a clear glass slide. All smears were fixed in $95 \%$ ethanol for 30 minutes. The AgNOR staining was performed by the method of Smith and Crocker. ${ }^{13}$ Briefly, all specimens were rehydrated with distilled deionised water. The AgNOR solution was prepared by dissolving gelatin in $1 \mathrm{~g} / \mathrm{dl}$ aqueous (distilled deionised) formic acid at a concentration of $2 \mathrm{~g} / \mathrm{dl}$. This solution was mixed (1:2 volumes) with $50 \mathrm{~g} / \mathrm{dl}$ aqueous (distilled deionised) silver nitrate solution to make the final working solution. This was immediately poured over the specimens and left for 30 minutes at room temperature in the dark. The silver colloid was washed off with distilled deionised water and the specimens dehydrated through graded ethanol to xylene and mounted in a synthetic medium. All specimens were examined using a $\times 100$ oil immersion objective for a total magnification of $\times 1000$. Atypical cells and/or reactive mesothelial cells were selected at random for the counting procedure. In each specimen the number of AgNOR dots was counted in 100 cells with the aid of a graticule, adjusting the focus carefully to enable clear identification of an AgNOR dot. The mean (SD) number of AgNORs per nucleus was calculated for each specimen.

\section{STATISTICAL ANALYSIS}

The data were analysed by the Student's unpaired $t$ test and $\chi^{2}$ test. Linear regression was used to compare the data obtained with the AgNOR technique, DNA index, and flow cytometric $S$ phase fraction analysis methods. Statistical significance was defined as $\mathrm{p}<0 \cdot 05$.

\section{Results}

Seventy one pleural effusions were studied and the relation between NOR and flow cytometry DNA analysis was also investigated. Thirty eight patients had pleural effusions caused by benign disease and 33 had adenocarcinoma of the lung. The results were confirmed by histopathology or patient follow up.

\section{CYTOLOGICAL ANALYSIS}

Four of 33 patients with malignant tumours had negative results at cytological examination (table 1). Also, two of the 38 patients with benign diseases were considered to have cells suspicious of malignancy. After following up these two cases, an inflammatory cause was diagnosed and the effusions subsided with appropriate management. Conventional cytology therefore had a $95 \%$ specificity and an $88 \%$ sensitivity (table 2 ).

Table 1 Results of analysis of pleural effusions by conventional cytology and flow cytometry

\begin{tabular}{lllllll}
\hline & \multicolumn{2}{l}{ Cytology } & & & \multicolumn{2}{c}{ Flow cytometry } \\
\cline { 2 - 4 } \cline { 6 - 7 } Effusions & Negative & Suspicious & Positive & & Diploid & Aneuploid \\
\hline Malignant & 4 & 3 & 26 & 16 & 17 \\
Benign & 36 & 2 & 0 & 38 & 0 \\
Total & 40 & 5 & 26 & 54 & 17 \\
\hline
\end{tabular}


Table 2 Comparative results with conventional cytology and flow cytometry

\begin{tabular}{llcr}
\hline & Cytology & Flow cytometry & Combined \\
\hline Sensitivity & $88 \%$ & $52 \%$ & $94 \%$ \\
Specificity & $95 \%$ & $100 \%$ & $100 \%$ \\
Predictive value of negative result & $90 \%$ & $70 \%$ & $95 \%$ \\
Predictive value of positive result & $94 \%$ & $100 \%$ & $100 \%$ \\
\hline
\end{tabular}

Sensitivity = true positive (TP)/TP + false negative (FN) )

Specificity = true negative (TN)/TN + false positive (FP)

Predictive value of negative result $=T N /(T N+F N)$

Predictive value of positive result $=$ TP $/(T P+F P)$

FLOW CYTOMETRIC DNA ANALYSIS

All 38 samples from patients without clinical evidence of malignancy were diploid. There were 17 aneuploid (52\%) and 16 diploid (48\%) DNA ploidy patterns in the 33 patients with malignancy (table 1). The DNA indices of the aneuploid tumours ranged from 1.93 to $1 \cdot 11$ with a mean (SD) of $1.42(0.25)$. Four of 33 patients with malignancy were cytologically negative for malignant cells, and two of these had aneuploid DNA results. However, another two had diploid DNA content by flow cytometry (table 3). The flow cytometry DNA analysis showed no false positive results and yielded $100 \%$ specificity. There were 16 false negative cases and the sensitivity was $52 \%$. The results obtained by both flow cytometry and conventional cytology were compared and yielded $94 \%$ sensitivity and $95 \%$ predictive value of a negative result. The combined specificity was $100 \%$ and the combined predictive value of positive results was $100 \%$ (table 2 ).

FLOW CYTOMETRY S PHASE FRACTION ANALYSIS In three of 17 aneuploid DNA histograms $S$ phase fraction analysis could not be performed due to complex histograms or excessive debris in the sample. The $S$ phase fraction was significantly increased in malignant cases $(n=30)$ compared with the benign cases $(n=38)(12.45$ $(3.93) \%$ v 5.32 (1.67)\%; $\mathrm{p}<0.0001)$. The aneuploid malignant cases had increased $S$ phase

Table 3 Comparison of results with flow cytometry and cytology in malignant cases

\begin{tabular}{lllll}
\hline \multirow{2}{*}{$\begin{array}{lllll}\text { Flow } \\
\text { cytometry }\end{array}$} & No. & Cytology & & \\
\cline { 3 - 5 } & of cases & Negative & Suspicious & Positive \\
\hline Diploid & 16 & 2 & 2 & 12 \\
Aneuploid & 17 & 2 & 1 & 14 \\
Total & 33 & 4 & 3 & 26 \\
\hline
\end{tabular}

Table 4 Mean (SD) data of flow cytometry $S$ phase fraction

\begin{tabular}{lcrl}
\hline & \multicolumn{2}{l}{$S$ phase fraction } & \\
\cline { 2 - 3 } & Range & Mean $(S D)$ & $p$ \\
\hline Malignant $(\mathrm{n}=30)^{*}$ & $20.5-6.2$ & $12.45(3.93)$ & $<0.0001$ \\
Benign $(\mathrm{n}=38)$ & $7.9-1.6$ & $5.32(1.67)$ & \\
Malignant* & & & \\
$\begin{array}{l}\text { Aneuploid }(\mathrm{n}=14) \\
\text { Diploid }(\mathrm{n}=16)\end{array}$ & $20.5-10.0$ & $15.89(2.36)$ & $<0.0001$ \\
\hline
\end{tabular}

*There were three histograms in which $S$ phase fraction could not be estimated from the histogram.

Table 5 Mean (SD) number of AgNOR dots per nucleus for malignant and benign pleural effusion cells

\begin{tabular}{llrl}
\hline & \multicolumn{2}{l}{ AgNOR } & \\
\cline { 2 - 3 } Effusions & Range & Mean $(S D)$ & $p$ \\
\hline Malignant & $18.94-5.67$ & $12.57(3.64)$ & $<0.001$ \\
Benign & $8.31-1.92$ & $3.92(1.39)$ & \\
\hline
\end{tabular}

fraction compared with the diploid malignant $\begin{array}{llllll}\text { cases } & (15 \cdot 89 & (2.36) \% & v & 9.44 & (2.09) \% \text {; }\end{array}$ $\mathrm{p}<0.0001$ ) (table 4). There was also an increase in the $S$ phase fraction associated with the diploid malignant cases compared with the diploid benign cases $(9.44(2.09) \%$ v $5.32(1.67) \%$; $\mathrm{p}<0.0001$ ) (table 4).

\section{AgNOR ANALYSIS}

The mean (SD) number of AgNOR dots per nucleus was 3.96 (1.39) (range 8.31-1.93) for cells from benign pleural effusions and $12 \cdot 57$ (3.64) (18.94-5.67) for the malignant pleural effusion cells $(p<0.001$; table 5$)$. The AgNOR dots were irregularly distributed and their size was highly variable in patients with malignant disease. The mean (SD) number of AgNOR dots was 14.45 (3.36) (range 18.94-8.93) for aneuploid malignant pleural effusion cells and $10.57(2.82)(16.24-6.03)$ for diploid malignant pleural effusion cells $(p<0.01 ;$ fig 1$)$. The AgNOR numbers were greater in diploid malignant effusion cells $(10.57(2.82))$ than in diploid benign pleural effusion cells $(3.96$ (1.39); $p<0.001$ ) (fig 1). The best cutoff point of the mean number of AgNOR dots per nucleus was determined by a receiver operative characteristic curve ${ }^{19}$ for predicting a malignant tumour in a patient with a pleural effusion. The selected value was $8 \cdot 0$, and there were two false negative cases and one false positive case. The sensitivity, specificity, and accuracy was 94\%, $97 \%$, and $96 \%$, respectively. The AgNOR numbers in two aneuploid malignant patients with negative cytology results were $11.6(2.56)$ and $8.93(2.38)$. Although the AgNOR num-

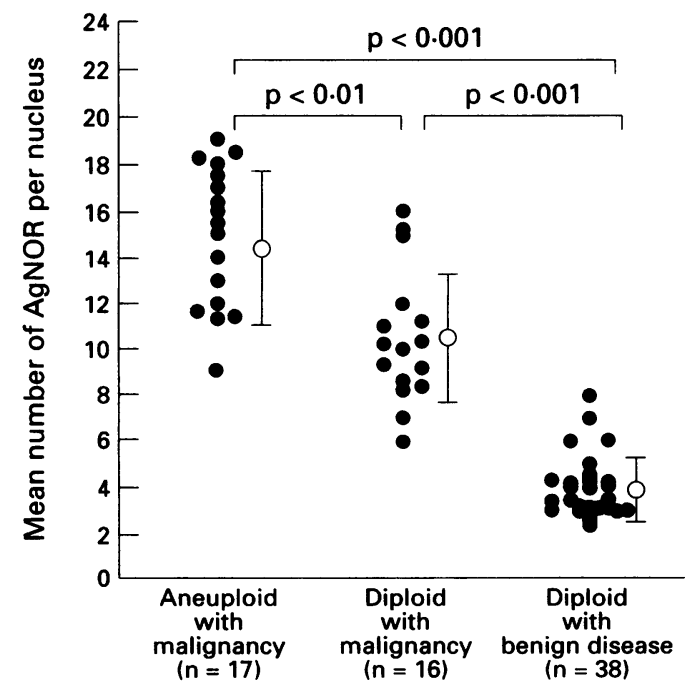

Figure 1 Scattengram to show distribution of the mean AgNOR number per nucleus for specimens examined. There was a significant difference among the three groups. 


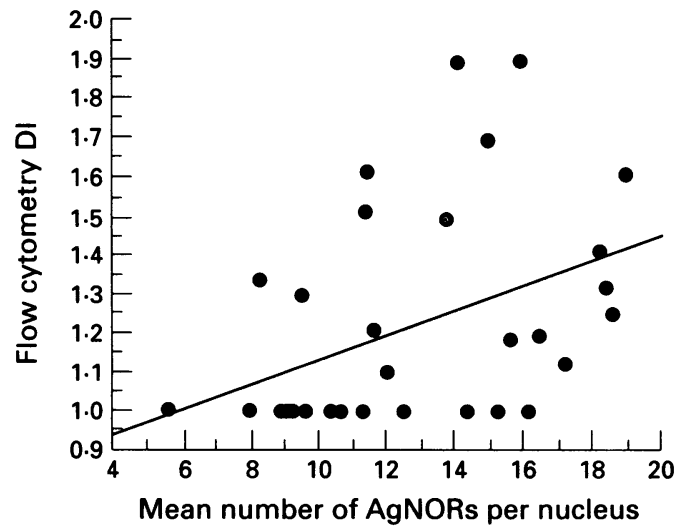

Figure 2 Correlation between the mean number of AgNORs per nucleus and flow cytometry DNA indices (DI) in 33 malignant cases $(\gamma=0.432, p<0.02)$.

bers of the two diploid malignant cases with negative cytology results showed less than 8 $(5.67(1.98)$ and $7.97(0.83))$, there were higher $S$ phase fractions $(8 \cdot 5 \%$ and $8 \cdot 8 \%$ ) than the mean number of $S$ phase fractions of benign cases $(5 \cdot 32 \%)$.

COMPARISON OF FLOW CYTOMETRIC DNA INDEX AND AgNOR TECHNIQUES

The mean DNA index of aneuploid tumours $(\mathrm{n}=17)$ was $1.43(0 \cdot 25)$ (range 1.11-1.92). There was no correlation between the flow cytometric DNA index and the mean number of AgNOR dots in aneuploid tumours. However, there was a weak correlation between the DNA index measured by flow cytometry and the mean number of AgNOR dots in malignant cases $(n=33, \gamma=0.432$, $p<0.02$; fig 2$)$.

COMPARISON OF S PHASE FRACTION DETERMINED BY FLOW CYTOMETRY AND AgNOR TECHNIQUES

The comparison of $S$ phase fraction determined by flow cytometry and the mean number of AgNOR dots in malignant cases showed a significant correlation $(n=30, \gamma=0.605$, $\mathrm{p}<0 \cdot 0005$ ) (fig 3).

\section{Discussion}

Flow cytometry is a process that can be used to determine cellular DNA content, cell cycle distribution kinetics, and chromesomal analysis among cell populations. ${ }^{1820-22}$ In contrast to mitotic karyotyping, the technique allows investigation of interphase cells and is not limited by the proliferative status of the cell population. The $S$ phase fraction measured by flow cytometry provides an important predictor of prognosis in some cancers. ${ }^{2324}$ Clark et $a l^{25}$ showed that diploid tumours with a higher $S$ phase fraction had a poorer prognosis than diploid tumours with a lower $S$ phase fraction. The $S$ phase fraction was significantly increased in malignant cases compared with benign controls. Aneuploid tumours have an increased $S$ phase fraction compared with diploid tumours. ${ }^{23}$ In our study malignant cases had a significantly higher $S$ phase fraction than the benign cases. The $S$ phase fraction was increased in aneu-

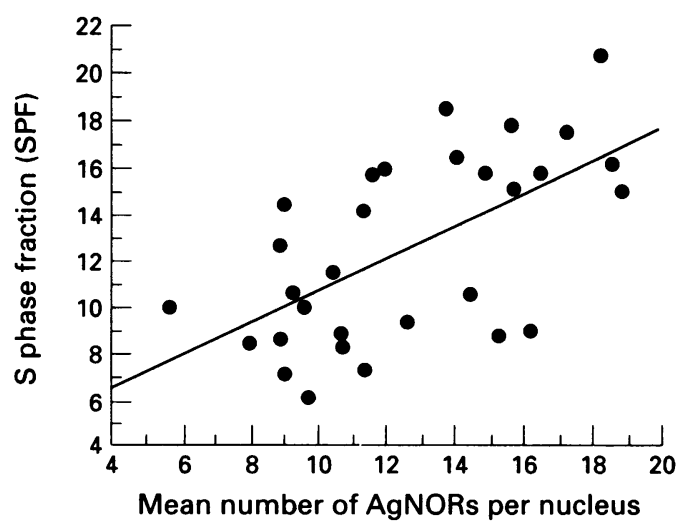

Figure 3 Correlation between the mean number of AgNORs per nucleus and flow cytometrically determined $S$ phase fraction in 30 malignant cases $(\gamma=0.605$, $p<0.0005$ ).

ploid malignant cases compared with diploid malignant cases.

Nearly all malignant neoplasms have chromosomal aberrations. However, the sensitivity of flow cytometric DNA analysis requires a significant quantitative DNA abnormality for detection. ${ }^{26}$ In addition, some tumours have chromosomal deletions and duplications that may balance out, resulting in a tumour cell with normal net DNA content by both karyotypic quantitation and flow cytometry but an obviously abnormal karyotype. ${ }^{26}$ Moreover, flow cytometric DNA analysis requires sufficient cells with a DNA abnormality to be detected. Malignant tumours with undetectable abnormal genomes are not uncommon.

Hedley et $a l^{9}$ reported $36 \%$ and Weissman et $a l^{7} 43 \%$ false negative rates in flow cytometric analysis of the DNA content of pleural effusions. There was a $48 \%$ false negative rate by flow cytometry in this study. Obviously flow cytometric DNA ploidy abnormality is not an appropriate diagnostic screening criterion of malignancy and contributes to the significant false negative rate. Our flow cytometric DNA content studies contained no false positive cases and yielded a specificity of $100 \%$. Similar results have been described by others. ${ }^{891827}$ However, $1-3 \%$ false positive rates with flow cytometry have been reported in effusion studies. $^{28-30}$

As the DNA of nucleolar organiser regions is transcribed ultimately into ribosomal RNA and hence leads to protein synthesis, the number or size of NORs might be expected to reflect cellular activity, proliferation, or transformation. Crocker et $a l^{1531}$ reported the application of the AgNOR technique to diagnostic tumour pathology. The AgNOR technique has been applied to metaphase chromosome spreads $^{12}$ and has been used to identify atypical chromosomes in certain malignancies. ${ }^{153132}$ The number of AgNOR dots within nuclei has been shown to differ in many benign and malignant tumours. ${ }^{13151731-33}$ Ayres et $\mathrm{al}^{34}$ reported that the reactive pleural diseases had significantly higher AgNOR numbers than normal pleura obtained by biopsy. Some studies have described a considerable overlap of AgNOR numbers between benign and malignant conditions. ${ }^{35}$ Our study showed that 
the interphase NOR count permits significant differences between malignant and benign pleural effusions. Aneuploid malignant patients also had significantly higher AgNOR numbers than diploid malignant patients.

Several methods for assessing cell proliferation and assisting in tumour grading have recently been introduced. $\mathrm{Ki}-67$ immunostaining and BrdU labelling are known to label replicating cells. However, these methods are restricted to frozen samples or are dependent on the intraoperative application of myelotoxic substances. Ki-67 immunostaining and AgNOR staining would appear to yield comparable data in non-Hodgkin's lymphoma, ${ }^{36}$ but the AgNOR technique has the advantage of being applicable to fixed and processed paraffin sections.

A recent comparison of NOR counts and flow cytometric DNA analysis of non-Hodgkin's lymphoma showed a very good linear correlation between the mean numbers of AgNOR sites and the percentage of $S$ phase cells. However, the correlation with tumour cell ploidy was poor. ${ }^{37}$ Schwarzacher et $a l^{38}$ showed that aneuploid cells have an increased number of chromosomes and chromosome arms that may bear additional NOR material. Thus, higher AgNOR counts for aneuploid tumours would be expected. Recently, Carbajo et $a l^{39}$ showed that the AgNOR technique can be considered as a cell proliferation marker. They also confirmed that AgNOR numbers were significantly higher in aneuploid than in diploid malignant pleural effusions.

We conclude that flow cytometry and the AgNOR technique provide comparable measurements in the diagnosis of pleural effusions. However, the AgNOR technique is rapid, simple and inexpensive and may be used routinely in diagnostic cytopathology. The present study has shown that the AgNOR staining technique may be used as a very useful adjunct to flow cytometric DNA content analysis, S phase fraction and conventional cytology in the diagnosis of malignant pleural effusions. Nevertheless, AgNOR staining has the advantage over flow cytometric DNA analysis of being applicable to routinely processed pleural effusions.

The authors are grateful to Miss Yu-Ling Wang and ShowChung Lin for their technical assistance.

1 Koss LG. Diagnostic cytology and histopathologic bases. 3rd edn. Philadelphia: JB Lippincott, 1979:921.

2 Domagala W, Koss LG. Configurations of surfaces of cells in effusion by scanning electromicroscopy. In: Koss LG, in effusion by scanning electromicroscopy. In: Koss LG, Coleman DV, eds. Advances in clinical

3 Coleman DV, Ormerod MB. Tumor markers in cytology. In: Koss LG, Coleman DV, eds. Advances in clinical cytology. Vol 2. New York: Masson, 1981:33-48.

4 Sandberg AA, Yamada K, Kinuchi Y, Tekagi N. Chromosomes and causation of human cancer and leukemia: III. Karyotypes of cancerous effusions. Cancer 1967;20: 1099-116.

5 Barlogie B. Abnormal cellular DNA content as marker of neoplasia. Eur f Cancer Clin Oncol 1984;20:1123-5.

6 Barlogie N, Derwinko D, Shumann J, Gohde W, Dosik G, Lateille J, et al. Cellular DNA content as a marker of neoplasia in man. Am $\mathcal{F}$ Med 1980;69:195-203.

7 Frankfurt OS, Slocum HK, Rustum YM, Arbuck SG, Pavelic ZP, Petrelli N, et al. Flow cytometric analysis of DNA aneuploidy in primary and metastatic human solid tumors. Cytometry 1984;5:71-80.

8 Evans DA, Thornwaite JT, Ng APB, Sugarbaker EV. DNA flow cytometry of pleural effusions: comparison with pathology for diagnosis of malignancy. Anal Quant Cytol 1983 5:19-27.

9 Hedley FW, Philips J, Rugg CA, Taylor IW. Measurement of cellular DNA content as an adjunct to diagnostic cytology in malignant effusions. Eur $\mathcal{F}$ Cancer Clin Oncol 1984; 20:749-52.

10 Hostmark J, Vigander T, Skaarland E. Characterization of pleural effusions by flow cytometric DNA analysis. Eur $\mathcal{f}$ Respir Dis 1985;66:315-9.

11 Henderson AS, Warburton D, Atwood KC. Location of ribosomal DNA in the human chromosomal complement. ribosomal Natl Acad Sci USA 1972;69:3394-8.

12 Howell WM, Black DA. Controlled silver staining of nucleolar organizer regions with protective colliodal developer: ane-step method. Experientia 1980;36:1014-5.

13 Smith R, Crocker J. Evaluation of nucleolar organizer regionassociated proteins in breast malignancy. Histopathology 1988;12:113-25.

14 Fallowfield ME, Dodson AR, Cook MG. Nucleolar organizer regions in melanocytic dysplasia and melanoma. Histopathology 1988;13:95-9.

15 Crocker J, Nar P. Nucleolar organizer regions in lymphomas. f Pathol 1987;151:111-8.

16 Crocker J, McGovern J. Nucleolar organizer regions in normal cirrhotic and carcinomatous livers. $\mathcal{F}$ Clin Pathol 1988;41:1044-8.

17 Crocker J, Skilbeck N. Nucleolar organizer region-associated protein in cutaneous melanotic lesions: a quantitative study. $\mathcal{F}$ Clin Pathol 1987;40:885-9.

18 Schneller J, Eppich E, Greenebaum E, Elequin F, Sherman $\mathrm{A}$, Wersto R, et al. Flow cytometry and Feulgen cytophotometry in evaluation of effusions. Cancer 1987;59. 1307-13.

19 Hanley JA, McNeil BJ. The meaning and use of the area under a receiver operating characteristic (ROC) curve. Radiology 1982;143:29-36.

20 O'Hara M, Bedrossian C, Johnson T, Barlogie B. Flow cytometry in cancer diagnosis. Prog Clin Pathol 1984;9: 135-53.

21 Traganos F. Flow cytometry: principles and applications. I Cancer Invest 1984;2:149-63.

22 Traganos F. Flow cytometry: principles and applications II. Cancer Invest 1984;2:239-58.

23 Dawson AE, Norton JA, Weinberg DS. Comparative assessment of proliferation and DNA content in breas carcinoma by image analysis and flow cytometry. $A m \mathcal{F}$ Pathol 1990;136:1115-24.

24 Merkel DE, McGuire WL. Ploidy, proliferative activity and prognosis. Cancer 1990;65:1194-205.

25 Clark GM, Dressler LG, Owens MA, Pounds G, Oldaker T, McGuire WL. Prediction of relapse or survival in patients with node-negative breast cancer by DNA flow pytometry. $N$ Engl $\Im$ Med 1989;10:627-33.

26 Zarbo RJ, Babu VR, Crissman JD. Sensitivity of flow cytometric DNA analysis of deparaffinized nuclei from urothelial carcinomas with near-diploid karyotypes. Lab Invest thelial carcinomas

27 Weissman GS, KcKinley MJ, Budman DR, Caccese WJ, Schulman P, Grueneberg D, et al. Flow cytometry: new technique in diagnosis of malignant ascites. $\mathcal{F}$ Clin Gastroenterol 1987;9:599-602.

28 Katz RL, Johnson TS, Williamson KD. Comparison of cytologic and acridine-orange flow cytometric detection of malignant cell in human body cavity fluids. Anal Quant Cytol Histol 1985;7:227-35.

29 Unger K, Raber M, Bedrossian C, Stein DA, Barlogie B. Analysis of pleural effusion using automated flow cytometry. Cancer 1983;52:873-7.

30 Stonesifer KJ, Xiang J, Wilkinson EJ, Bensen NA, Barlan RC. Flow cytometric analysis and cytopathology of body RC. Flow cytometric analysis and cytopa

31 Crocker J, Ayres J, McGovern J. Nucleolar organizer regions in small cell carcinoma of bronchus. Thorax 1987;42. $972-5$.

32 Ploton D, Menager $M$, Adent J. Simultaneous high resolution localization of $\mathrm{AgNOR}$ proteins and nucleoproteins interphasic and mitotic nuclei. Histochem $\mathcal{f} 1984$ 16:897-906.

33 Huang MS, Hwang JJ, Tsai MS, Wang TH, Lin MS, Chong IW, et al. Application of staining of nucleolar organizer regions in cytological smears of bronchus. Kaohsiung $\mathcal{F}$ Med Sci 1992;8:136-40.

34 Ayres J, Crocker J, Skilbeck N. Differentiation of malignan from normal and reactive mesothelial cell by the argyrophil trom normal and reactive mesothelial cell by the argyrophil technique for nucleolar organ

35 Nairn ER, Crocker J, McGovern J. Limited value of AgNOR enumeration in the assessment of thyroid neoplasms. $f$ Clin Pathol 1988;41:1136.

36 Hall PA, Crocker J, Watts A, Stansfeld AG. A comparison of nucleolar organizer regions staining and $\mathrm{Ki}-67 \mathrm{im}-$ munostaining in non-Hodgkin's lymphoma. Histopathology 1988;12:373-81.

37 Crocker J, Macartney JC, Smith PJ. Correlation between DNA flow cytometric and nucleolar organizer region dat in non-Hodgkin's lymphoma. $\mathcal{F}$ Pathol 1988;154:151-6.

38 Schwarzacher RT, Kraemer PM, Cram LS. Spontaneous in vitro neoplastic evolution of cultured Chinese hamster cells. Nucleolus organizing region activity. Cancer Genet Cytogenet 1988;35:119-28.

39 Carbajo S, Orfao A, Vicente-Villardon JL, Carbafo-Perez E. Expression of silver-stained nucleolar organizer regions is coupled to cell cycle in rat thymic cells. Cytometry 1993; 14:46-52. 